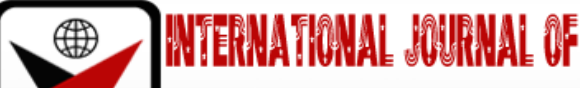 \\ בाma
}

ISSN 2278 - 0211 (Online)

\section{Performance of Events Management Service Providers within the Weddlings Subsector, in Nairobi County, Kenya}

Kinuthia, Teddy Kariuki
Student, Department of Hospitality Management, University of Nairobi,
Kenya Utalii College Campus, Kenya
Evaline, Kimanga
Lecturer, Department of Hospitality Management, Kenya Utalii College, Kenya
Dr. Jane Wanjiku
Academic Writing Couch, Pan Africa Christian University, Kenya

\section{Abstract:}

The purpose of the study was to investigate the factors influencing performance of events management service providers in Nairobi County, Kenya with a view to highlight the most salient determinants of event management success. Event Management Body of Knowledge (EMBOK) constituted the theoretical framework for this research. The study adopted a descriptive research design. The population of the study was 196 event management companies in Nairobi. A modest sample of 39 of the companies was selected using stratified random technique. Data was collected using a structured questionnaire. Descriptive statistical techniques such as percentage frequencies, mean and standard deviations was used to analyze data. The data was presented in the form of frequency tables, charts and graphs for ease of analysis and interpretation. The study established that in terms of performance rating, customer satisfaction was the highest $(M=4.77, S D=0.430)$, followed by time efficiency $(M=4.70, S D=0.466)$, and budget efficiency $(M=3.37, S D=0.490)$ while profitability was the least rated on a 5-point scale $(M=2.97, S D=0.718)$. The results showed that on aggregate, event risk factors potentially had the greatest influence on wedding event management performance ( $M=4.43$, $S D=0.549)$, followed by event administration factors $(M=4.30, S D=0,604)$ and lastly, event operation factors $(M=4.19$, $S D=0.576)$. The study concluded that Event risk factors was the most salient determinant of event management success. This was reflected in the emphasis put on astuteness in decision making as a basic requirement for surviving and thriving in the wedding event management business as well as risk prevention measures through detailed security, health and safety measures as well as legal compliance to mitigate risks. Event operation followed as the second EMBOK domain that potentially influenced performance of wedding event management service providers. A number of event operation factors were especially salient such as the experience of the staff team. Time management was also a critical success factor in tow, as was budgetary issues, whereby difficulty in accurately estimating the budget due to price fluctuations was a key challenge confronting player in the wedding industry. Event operation factors also did potentially influence performance of wedding event management companies although not as much as event risk or administration domains. The study recommends that event management companies should develop risk-adjusted budgets that should inform quotation decisions. Wedding budgets need to be informed by a thorough research and forecasting of future prices and changes that may take place as the event date neared. In order to reduce exposure to price fluctuations and enhance budget efficiency, event management companies should sign hedge contracts with the main vendors and suppliers in a wedding. Further, the experience of the staff needs to form the basis of hiring decisions in an event management firm. These findings could be useful to events management service providers as they seek to deliver quality services to their clients.

Keywords: EMBOK, events management, factors, performance, service providers

\section{Introduction}

Event management is the application of project management concepts to the planning and realization of social occasions (Kimani, 2014). It is the process of planning, preparing and producing an event (Lopacinska, 2013). Wabuyele (2017) traces the history of event management industry to the $19^{\text {th }}$ century when it first became formalized as a profession. The industry developed out of the need for accommodating, refreshing and entertaining guests (Owusu-Mintah \& Dacosta, 2017). The industry has witnessed rapid growth in recent decades (Kashef, 2015).

Today, the event management industry has become an important contributor to economic growth in many nations. The global event management industry is valued in billions of dollars as more than 500 billion US dollars is spent annually on planned events around the world (Wanjiru, 2012). For instance, events are an important contributor to the British economy, with the sector currently adding a net worth of between $£ 22$ billion and £ 36 billion per annum to the 
national economy. In addition, employment estimates for the industry stand at around 530,000 in the UK, with 15,500 working in business events such as conferences, events, and exhibitions (Abson, 2017).

In Africa, event management industry has witnessed a rapid growth, whereby in some countries such as South Africa, it is a multi-million-rand industry that is gaining international recognition (Kimani, 2014). Similarly, Wanjiru (2012) notes that events management companies have also been on the rise in Kenya. Agreeing with this observation, Kimani (2014) comments that event management in Kenya has indeed changed the way we handle our events; it's not only done for lavish parties, weddings and big companies who hire managers to help in organizing and planning their events but clients who have small budgets are also getting help from event managing companies.

Event management business has and continues to gain more attention among scholars owing to the exponential growth witnessed in the events industry in the recent past (Korir, 2018). Commentators like Abson (2017) go as far as asserting that event management is a field of industrial practice, which involves the organization and coordination of the activities required to achieve event objectives. Broadly, the events sector can be seen to consist of the following categories: business or corporate events, leisure events, cultural events and hospitality events.

As the event management industry grows, there has been a corresponding growing concern about the performance of event management service providers (Njoroge, 2018; Srivastava \& Maitra, 2016). However, performance in the industry has been conceptualized differently, from meeting of client expectations, to quantitative measures such as profitability and cost efficiency, to achievement of objectives (Kimani, 2014; Kukushkina, 2016; Wahab, Shahibi, Ali, Bakar, \& Amrin, 2014). For instance, Kimani (2014) conceptualized performance of event management as measured by profitability, sustainability and cost efficiency. Korir (2018) on his part suggest that the performance of these ventures could best be measured using the balanced scorecard factors namely: learning and growth, internal business processes alignment, customer satisfaction, and financial performance. Kukushkina (2016) however argue that the most important yardstick for measuring performance of event service providers is the extent to which they meet the expectation of the clients and the participants of the event. This is closely related to the approach of Wahab et al. (2015) who defines event success as the achievement of some desired objective which may be to gain profit.

Irrespective of the yardstick used to measure performance, attention has been called to the factors that influence performance in the event management industry (Owusu-Mintah \& Dacosta, 2017). A myriad of factors may be influencing performance of event management service providers as event management typically involves undertaking projects that are creative, complex, problematic, dynamic and stakeholder reliant (Abson, 2017). Meticulous planning and careful management are identified as the common denominator of all successful events (Owusu-Mintah \& Dacosta, 2017). An event planner is therefore a person or organization that is tasked with the duties of event planning (Kimani, 2014). The ability to collaborate with other vendors is crucial during an event no matter whether a business has worked with these vendors before. Customers pay attention to whether a business uses good vendors and also how they coordinate numerous vendors (Shi, 2020). In addition, time management is also recognized as the essence of success for any event (Ahmad, Yusuf, \& Wahab, 2012).

Scholars agree that the recent growth of events industry around the world means that the management of events can no longer be ad hoc. As such, events are increasingly having a large impact on communities and, in some instances, have significant socioeconomic implications nationally (Kimani, 2014; Njoroge, 2018). It is this realization that saw the development of Event Management Body of Knowledge (EMBOK) - a holistic framework that offers a logical and systematic approach to professional event management (Makda, Bayat, \& Ukpere, 2012). This framework identifies five knowledge domains that are critical for event management success: event administration, event design, event marketing, event operation and event risks (Makda et al., 2012). These domains represent the full scope of work that clients typically assign to event managers (Silvers, 2007).

Event administration is concerned with issues to do with finance, human resource, information management, procurement, stakeholder management, systems and time management; design encompasses elements such as food and refreshment, content, entertainment, environment, production, programme and theme design; marketing addresses related issues of planning, merchandise, promotion, public relations, sales and sponsorships; event operations attends to issues such as attendee management, communication, infrastructure, logistics, participants, site and technical management; lastly, risk factors encompass compliance, decision risk, emergency, health and safety, legal and security issues ( Makda et al., 2012). This study investigated how these factors influence the performance of event management service providers in Kenya's wedding sub-sector.

The wedding sub-sector is one of the fastest growing industry in the broader hospitality industry in Kenya, thanks to a growing middle class with a penchant for western ideas of a wedding otherwise known as white weddings (Goldsmith, 2018). Media reports reveal that the wedding industry generates more than Ksh.30 billion annually, with an average of 28,000 Kenyans getting wedded every year and spending anywhere from half a million to even over 40 million (Mwanza, 2019). It is a fledgling sub-sector characterized with fast growth complete with expos and industry awards. This has attracted many event planners, with a growing number of event management companies being registered annually (Korir, 2018).

\section{Statement of the Problem}

A wedding event is a lifetime investment which must prove its worth to the couple as it marks a new chapter in the couple's life (Kukushkina, 2016). Getting everything right the first time is therefore crucial to event management success as the temporary nature of events provide only one opportunity to get it right, and offers few opportunities to redress mistakes - some of which can have far reaching implications which often cannot be corrected (Abson, 2017). Yet although there is a growing realization that event management can no longer be handled in an ad hoc manner (Kimani, 
2014; Njoroge, 2018), there is limited application of EMBOK to the study of factors influencing performance of event management service providers in Kenya's fast growing wedding sub-sector.

Kimathi (2014) researched the factors influencing the performance of events management firms in Nairobi, Kenya. Using a sample of 31 respondents, the study found out that supply chain networks, management skills in supply chain and access to credit facility influence the performance of the event management industry. However, although the study revealed some insights that can be applicable to all events, it did not highlight the factors that are unique to the wedding sub-sector. Further, performance was measured in the study in terms of profitability, sustainability and costefficiency, which are inadequate for evaluating performance in the wedding-subsector.

Njoroge (2018) studied the effect of strategic planning on performance of event planning firms in Nairobi. The findings strongly acknowledged that strategic planning is the foundation that improves the business processes and ultimately reduces the internal costs of operation. However, the study also pointed out that by focusing on specific sectors, new knowledge can be generated with respect to the unique factors that are salient to each sector.

The problem addressed by the current research is that there is limited application of EMBOK to the investigation of the factors influencing performance of event management service providers in Kenya. Focusing on the wedding subsector, the study sought to address this knowledge gap by examining three domains for which there is the least empirical knowledge: event administration, event operation and event risks.

\section{Materials and Methods}

The study adopted a descriptive research design which according to Creswell (2014), focuses on description of research results in answer to the 'what?' aspects of a study. For this reason, the research design was considered most appropriate because it enabled the research to establish what factors influence performance of event management service providers.

The target population was the managers of organizations that were selected for this project. The distinguishing characteristics for these people are that they are managers of organizations that deal with events management within Nairobi County. According to Yellow Pages Kenya Directory, there were 196 event management companies in Nairobi as of October 2020. Table 1 below provides the population distribution classified in wedding supplies and services (event companies dealing exclusively with wedding events) and general event organizers (event companies dealing with all types of events).

\begin{tabular}{|c|c|c|}
\hline Category & Population & Percent \\
\hline Wedding supplies and service companies & 56 & $29 \%$ \\
\hline General event organizers & 140 & $71 \%$ \\
\hline Total & 196 & $100 \%$ \\
\hline
\end{tabular}

Table 1: Population Distribution

For Sampling and sample size, stratified random sampling technique was used. This is whereby the sample is chosen in proportion to its share of the total population so as to ensure inclusion of wedding supplies and service companies and general event organizers into the sample (Dunscomb, 2014). According to Mugenda and Mugenda (2003), a sample of 10 to 30 percent of the population is adequate. In this study, the sample size was 39 event management service providers, representing $20 \%$ of the population size. Table 2 presents the sample size distribution.

\begin{tabular}{|c|c|c|c|}
\hline Category & Population & Sample & Percent \\
\hline Wedding supplies and service companies & 56 & 11 & $29 \%$ \\
\hline General event organizers & 140 & 28 & $71 \%$ \\
\hline Total & 196 & 39 & $100 \%$ \\
\hline
\end{tabular}

Table 2: Sample Size Distribution

Data was collected using a structured questionnaire. The procedure of data collection involved seeking for permission from the administration of the various organizations so that the researcher is able to administer questionnaires. Each respondent was requested to sign a consent form to show that they are providing the information voluntarily. The researcher assured them of confidentiality of the information given.

Data was coded and analyzed as per the research objectives. As Mugenda and Mugenda (2003) observes, data analysis process enables researchers to make sense of the data and bring meaning to the raw data collected from the questionnaires. The data was presented in the form of frequency tables, charts and graphs for ease of analysis and interpretation.

\section{Analysis and Discussion}

In this section, results on the factors influencing performance of events management service providers are presented, followed by a discussion of their implications. This way, the most salient determinants of event management success are identified and explained. 


\subsection{Descriptive Overview of Events Companies in Nairobi}

Out of a total of 39 event management companies sampled for this study, only 30 successfully responded to the questionnaire which translated into 77 percent response rate. This however corresponds with Groves, Fowler, Couper, Lekowski, Singer and Tourangeau's (2009) argument that response rates of over 70 percent are very good. Similarly, Fincham (2008) observes that researchers should endeavor to attain a response rate of at least 60 percent, thereby validating the response rate obtained in the current study which has surpassed this threshold.

Wedding events management companies are either owned by individual proprietors, as partnerships or as limited companies. An observation of the study is that partnership firms which constituted $50 \%$ in this study are more popular probably because they involve joint efforts of two or more entrepreneurs in a bid to leverage their human and material resources to realize higher performance. The study also established that rarely do these companies exclusively manage weddings only but rather they manage other types of events as well. Ninety-three per cent of respondents indicated that they manage all kinds of events. These results suggest that most of the event companies diversified their services, perhaps as a way of creating multiple revenue streams.

On the issue of how long the companies have been in operation, the study established that $40 \%$ of the event companies had been in operation for 6 to 10 tears and 30\% had been operating for over 10 years. However, some $27 \%$ of the companies had existed for between 3 to 5 years while $3 \%$ of the event firms were between 1 and 3 years old. This is as illustrated in the figure below.

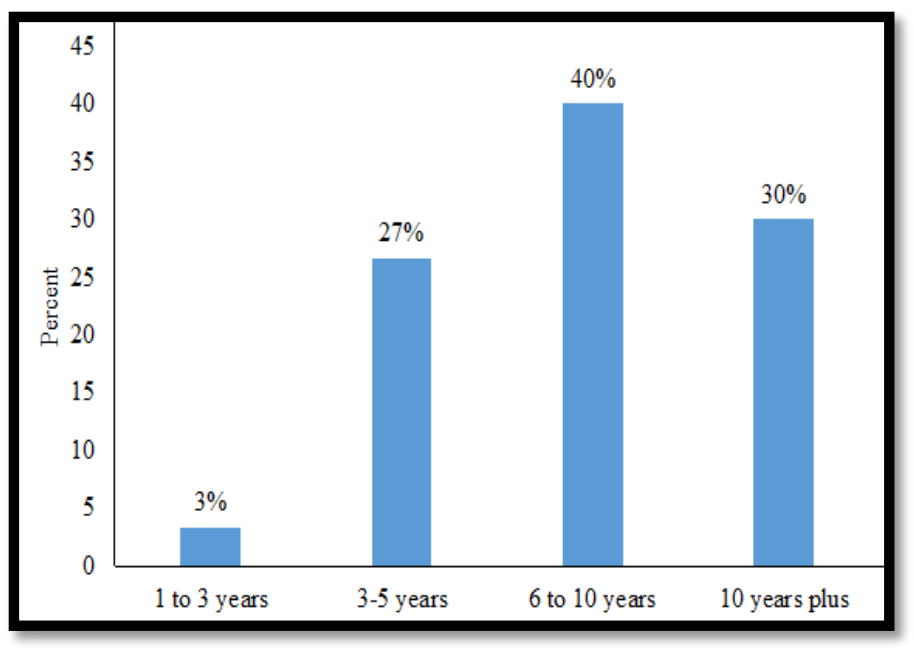

Figure 1: Age of Event Companies (Years of Operation)

The results suggest that majority of the companies had been in existence for at least 6 years, implying that they had been in operation for relatively long. This connotes possession of adequate industry experience as event service providers (Wanjiru, 2012).

On the issue of the number of employees in these companies, the study established that majority (40\%) of the event management service providers had between 5 to 10 employees, followed by $36.7 \%$ who had employed 11 to 20 staff and $16.7 \%$ with $21-50$ employees. Lastly, $6.7 \%$ of the firms had less than 5 employees. The results suggest that most of the event companies in Nairobi are small sized as there was no medium-sized or large event firm represented in the study.

\subsection{Performance of Event Management Companies}

Four performance dimensions were used to evaluate the performance of the event management service providers represented in the study: budget efficiency, time efficiency, profitability and customer satisfaction. Respondents rated the performance of their event companies on a 5 point-scale from very poor to very good. Table 3 presents the minimum (Min) score, the maximum (Max) score, the mean (M) score and the standard deviation (SD) score of the dataset.

\begin{tabular}{|c|c|c|c|c|}
\hline Performance Dimension & Min & Max & M & SD \\
\hline Customer satisfaction (client was happy) & 4 & 5 & 4.77 & 0.430 \\
\hline Time efficiency (event was on time) & 4 & 5 & 4.70 & 0.466 \\
\hline Budget efficiency (event was on budget) & 3 & 4 & 3.37 & 0.490 \\
\hline Profitability (event was profitable) & 2 & 4 & 2.97 & 0.718 \\
\hline Overall performance & 3 & 5 & 3.95 & 0.526 \\
\hline
\end{tabular}

Table 3: Descriptive Analysis of Performance of Event Management Companies

The table shows that a very high mean score was obtained in terms of customer satisfaction $(M=4.77, S D=0.430)$ and time efficiency $(M=4.70, S D=0.466)$, suggesting that the event management companies were highly performing in terms of keeping the clients happy and delivering the event on time. However, the companies recorded a moderate mean score in terms of budget efficiency $(M=3.37, S D=0.490)$ and profitability $(M=2.97, S D=0.718)$ implying that the event companies were recording average performance in their ability to keep events on budget and profitable. In terms of overall performance, a high mean score was computed $(\mathrm{M}=3.95, \mathrm{SD}=0.526)$ meaning that the event management 
companies were generally performing well. The results suggest that the companies were recording better non-financial performance as compared to financial aspects of performance. The findings can be inferred to mean that wedding event management service providers did prioritize customer satisfaction and delivering events on time, signaling the importance of these two measures of performance for an event company. This is in line with the argument put forth by Kukushkina (2016) that the most important yardstick for measuring performance of event service providers is the extent to which they meet the expectation of the clients and keep participants of the events happy.

\subsection{Event Administration Factors Influencing Performance of Event Companies}

An objective of the study was to establish event administration factors influencing the performance of events management service providers in Nairobi County, Kenya. Descriptive analysis was performed to establish respondents' views on administration aspects of events such as budgeting, cash flow management, staffing, time management and stakeholder role clarification. Table 4 shows the minimum (Min), maximum (Max), Mean (M) and Standard Deviation (SD) scores.

\begin{tabular}{|c|c|c|c|c|}
\hline Item & Min & Max & $\mathbf{M}$ & SD \\
\hline $\begin{array}{l}\text { The experience of the staff team is of great essence to organizing } \\
\text { a successful wedding }\end{array}$ & 4 & 5 & 4.87 & 0.346 \\
\hline Time management is the most critical success factor in a wedding & 4 & 5 & 4.63 & 0.490 \\
\hline $\begin{array}{l}\text { There is need to clarify role of each stakeholder to realize results } \\
\text { in a wedding. }\end{array}$ & 4 & 5 & 4.47 & 0.507 \\
\hline $\begin{array}{l}\text { Preparing an accurate budget is always difficult due to changing } \\
\text { costs of items. }\end{array}$ & 3 & 5 & 4.33 & 0.606 \\
\hline $\begin{array}{c}\text { Wedding budgets are always exceeded due to unforeseen } \\
\text { expenses. }\end{array}$ & 3 & 5 & 4.27 & 0.640 \\
\hline $\begin{array}{l}\text { Performance is dependent on adequate upfront payment from } \\
\text { clients. }\end{array}$ & 1 & 5 & 3.80 & 0.997 \\
\hline $\begin{array}{l}\text { Detailed evaluation of event income and expenditure is necessary } \\
\text { to succeed. }\end{array}$ & 3 & 5 & 3.73 & 0.640 \\
\hline Aggregate of event administration factors & 3 & 5 & 4.30 & 0.604 \\
\hline
\end{tabular}

Table 4: Event Administration Factors Influencing Performance

Table 4 shows that on a 5-point scale the mean score for the statement, 'the experience of the staff team is of great essence to organizing a successful wedding' was very high $(\mathrm{M}=4.87, \mathrm{SD}=0.346)$. This means that the majority of the respondents strongly agreed that experience of the human resource greatly influence event management performance. This agrees with the observation by Owusu-Mintah and Dacosta (2017) that event managers often depend on their experiences to organize events.

Similarly, the mean score obtained for time management was very high $(M=4.63, S D=0.490)$ implying that respondents strongly agreed that time management was the most critical success factor in a wedding. This finding affirms Ahmad et al.'s (2012) recognition of time management as the essence of success for any event. This was expected since by nature, all events are time-sensitive and, for a wedding event that in most cultures, is a one-day affair, time management is a key success factor.

The study also found that a high mean scores on a scale of 1 to 5 was obtained for the statement, 'there is need to clarify role of each stakeholder to realize results in a wedding' ( $M=4.47, \mathrm{SD}=0.507)$, which means that on aggregate, respondents agreed that stakeholder role clarification was central to the realization of desired results. This implies that stakeholder management potentially influenced event management performance. This finding is consistent with the results of a study by Kruger (2011) in South Africa which found that effective stakeholder role clarification was one of the critical success factors.

Table 4 further shows that the mean score on a scale of 1 to 5 was high for the statement, 'preparing an accurate budget is always difficult due to changing costs of items' $(M=4.33$. SD=0.606) as well as for the statement, 'wedding budgets are always exceeded due to unforeseen expenses' $(M=4.27, S D=0.640)$. These results suggest that wedding budgets were always overshot, which potentially negatively impacted on financial performance of the event management companies. The findings agree with Davies (2018) who pointed out that quite often, the budgets set at the planning stage are exceeded.

As shown in table 4, a moderately high mean score was obtained on a 5-point scale regarding whether performance was dependent on adequate upfront payment from clients $(M=3.80, S D=0.997)$. This means that most of the respondents agreed that adequate upfront payment from clients had an influence on event management performance. This finding affirms the idea that adequate financial resources plays a crucial role in the success of any event as was discovered in a study by Kokolakis (2018) who investigated sporting events organization and management.

Respondents were asked whether detailed evaluation of event income and expenditure is necessary to succeed. The results show that a moderately high mean score was computed on a 5 -point scale $(M=3.73, \mathrm{SD}=0.640)$, implying that most of the respondents agreed with the idea that a detailed evaluation of income and expenditure was needed to realize success. This is in harmony with Sondar (2005) who posit that the essence to successful event management entails an evaluation of the anticipated income and expenditure, budgeting and cash-flow. It means that in order for event managers 
to price their services accordingly, there is need to have a grasp of all the potential sources of revenue and cost items to develop the best budget estimate.

The overall mean score for event administration factors was high $(M=4.30, S D=0.604)$. This implies that on aggregate, respondents agreed that event administration factors did influence the performance outcomes of wedding event management companies. This finding affirms the relevance of event administration as a domain in EMBOK framework proposed by Slivers (2007) that managers need to competent at in order to realize performance and success in the wedding sub-sector.

\subsection{Event Operation Factors Influencing Performance of Event Companies}

Another objective of the study was to investigate event operation factors influencing the performance of events management service providers in Nairobi County, Kenya. In this section, the descriptive results are presented in terms of the minimum (Min), maximum (Max), mean (M) and standard deviation (SD) scores.

\begin{tabular}{|c|c|c|c|c|}
\hline Item & Min & Max & M & SD \\
\hline $\begin{array}{l}\text { Satisfying the wedding couple always require giving a good } \\
\text { experience to the wedding guests and attendees. }\end{array}$ & 4 & 5 & 4.70 & 0.535 \\
\hline $\begin{array}{l}\text { The site of a wedding often has far reaching implications on } \\
\text { the wedding budget. }\end{array}$ & 3 & 5 & 4.53 & 0.507 \\
\hline $\begin{array}{l}\text { Wedding planners must always watch for signs of } \\
\text { communication breakdown to ensure success. }\end{array}$ & 3 & 5 & 4.47 & 0.507 \\
\hline $\begin{array}{l}\text { A small disruption in the logistical aspects of a wedding can } \\
\text { have a significant impact on performance. }\end{array}$ & 1 & 5 & 3.07 & 0.753 \\
\hline Aggregate of event operation factors & 3 & 5 & 4.19 & 0.576 \\
\hline
\end{tabular}

Table 5 Event Operation Factors Influencing Performance

Respondents were asked whether satisfying the wedding couple always required giving a good experience to the wedding guests and attendees. As shown in table 5, a very high mean score was computed $(\mathrm{M}=4.70, \mathrm{SD}=0.535)$. This finding suggests that research participants were strongly in agreement with the statement. It can be surmised from this score that stakeholder dissatisfaction was a potential risk factor that can adversely impact on performance. The finding is in accord with the results of a study by Abson (2017), in which participating event managers described situations in which they needed to manage expectations of stakeholders and to look for a solution to satisfy all stakeholders. This may be explained by the mere fact that a wedding event is not just a service delivery to the wedding couple but a marketing event in which guests and attendees are prospective customers or sources of referrals.

The opinion of respondents was sought in regards to whether the site of a wedding often has far reaching implications on the wedding budget. The results in table 5 shows that the mean score on a 5 -point scale was very high $(\mathrm{M}=4.53, \mathrm{SD}=0.507)$. This means that majority of the respondents strongly agreed with the statement, which is an indication that location decisions potentially impacted on performance of event management companies in terms of budget efficiency. This finding is consistent with a research by Ismail (2014) who studied the critical success factors of event management in Malaysia. Just as in this study, the study by Ismael found that location of venue was one of the critical success factors to event management performance. It is also in agreement with Terzi et al.'s (2013) study of the impact of conference location on the performance of international events which revealed that event location influenced performance through resource allocation.

Table 5 further shows that a high mean score was obtained on a 5-point scale for the statement, 'wedding planners must always watch for signs of communication breakdown to ensure success' (M=4.47, $S D=0.507)$. This means that majority of the respondents agreed that communication breakdown was an operational factor influencing the performance of event planning companies. This is in line with a study done by Rofna (2009) on the critical success factors of a sporting event which identified communication as vital.

As pertains whether a small disruption in the logistical aspects of a wedding can have a significant impact on performance, a moderate mean score was established on a 5 -point scale $(\mathrm{M}=3.07, \mathrm{SD}=0.753)$. This suggests that small disruptions had limited adverse impact on event management performance. One reason that may explain this is that small disruptions allow room for adjustments. Further, while disruptions may have implications on time, the impact on actual or perceived performance may be minimal due to the influence of African culture that unlike the western world, is more flexible with perception of time and time management.

In summation, the results in table 5 indicate that on aggregate, the mean score for the influence of event operations was high $(M=4.19, S D=0.576)$, implying that respondents generally agreed that event operation factors had an influence on the performance of wedding event management companies. This finding agrees with EMBOK theory as propounded by Srivastava and Maitra (2016) who identified event operation as an important domain in the equation of event management success.

\subsection{Event Risk Factors Influencing Performance of Event Companies}

There was also the objective of determining how event risk factors influencing the performance events management service providers in Nairobi County, Kenya. Descriptive statistics of the responses to a 5-item Likert scale is presented in table 6. The table shows the minimum (Min), maximum (Max), mean (M) and standard deviation (SD) scores of respondents' opinion on a scale of 1 to 5 . 


\begin{tabular}{|c|c|c|c|c|}
\hline Item & Min & Max & M & SD \\
\hline $\begin{array}{c}\text { Decision making is a basic skill that every event manager must } \\
\text { have to be successful in the wedding industry. }\end{array}$ & 4 & 5 & 4.67 & 0.479 \\
\hline $\begin{array}{c}\text { We have to factor in detailed security measures in our planning } \\
\text { to prevent any security risks. }\end{array}$ & 4 & 5 & 4.63 & 0.490 \\
\hline $\begin{array}{c}\text { We always have to go to great length to prevent any health or } \\
\text { safety issue that may arise. }\end{array}$ & 4 & 5 & 4.50 & 0.509 \\
\hline $\begin{array}{c}\text { Event managers need to have an eye towards legal compliance } \\
\text { issues to avoid legal liability. }\end{array}$ & 4 & 5 & 4.33 & 0.479 \\
\hline $\begin{array}{c}\text { The legal liability to the company is always high whenever } \\
\text { something goes wrong in a wedding. }\end{array}$ & 3 & 5 & 4.00 & 0.788 \\
\hline Aggregate of event risk factors & 4 & 5 & 4.43 & 0.549 \\
\hline
\end{tabular}

Table 6: Event Risk Factors Influencing Performance

Table 6 indicates that the statement, 'decision making is a basic skill that every event manager must have to be successful in the wedding industry' yielded a very high mean score on a 5-point scale ( $M=4.67, S D=0.479)$, suggesting that respondents strongly agreed that there were potential decision risks that called for astute decision making to realize wedding event success.

As concerns whether event planners have to factor in detailed security measures in planning to prevent any security risks, a very high mean score was obtained $(S=4.50, S D=0.509)$. This means that majority of the respondents strongly agreed that detailed security measures had to be put in place to realize a successful event. It can be surmised from this finding that security was a risk factor with potential effects on performance of wedding event management companies. This agrees with the results of a study by Terzi et al. (2013) which also found that the criterion of security is one of the elements that seem to have a great impact on event success.

The opinion of respondents was sought in terms of whether they had to go to great length to prevent any health or safety issue that may arise. A very high mean score was computed on a 5-point scale $(M=4.50, S D=0.509)$, signaling the salience of health and safety as a risk factor potentially influencing wedding event management performance. This finding is in keeping with the results of Terzi et al.'s (2013) study which found that the evaluation criterion of health and safety measures such as hygiene is an important evaluation criterion. This may be because catering and reception is a key aspect of any wedding event and therefore, health and safety of guests and participants must be assured as a bad experience may not only have legal consequences but also paint a bad image of the event company.

Respondents were asked whether event managers need to have an eye towards legal compliance issues to avoid legal liability. A high mean score was obtained for this statement on a scale of 1 to $5(M=4.33, S D=0.479)$. Further, majority of the respondents agreed that the legal liability to the company is always high whenever something goes wrong in a wedding as indicated by a high mean score on a 5-point scale $(M=4.00, S D=0.788)$. This means that the majority of the respondents highly perceived legal liabilities to be a risk factor influencing performance of wedding event management companies. This finding agrees with the assertion by Abbott and Geddie (2001) that creating plans with an eye toward legal issues helps towards taking appropriate actions to mitigate potential legal risks.

Table 6 reveals that on aggregate, a high mean score was computed for the effect of event risk factors $(M=4.43$, $\mathrm{SD}=0.549$ ) which means that respondents generally agreed that event risk factors did influence wedding event management performance. This finding can be explained by the fact that wedding events typically involve the giving and receiving of gifts that need to be kept safe and secure from potential theft, damage or loss. Reid and Ritchie (2011) pointed out that events typically draw large crowds of people together within defined spaces and as such have the potential to introduce risks that make the capacity of event service providers to deal with risks and crisis important considerations for the performance and sustainability of event management companies.

\subsection{Implications of the Factors That Influence Performance of Wedding Events Service Providers}

Event risk factors were the most salient determinant of event management success. This was reflected in the emphasis put on astuteness in decision making as a basic requirement for surviving and thriving in the wedding event management business as well as risk prevention measures through detailed security, health and safety measures as well as legal compliance to mitigate risks. This has direct budgetary implications on event management service providers who shoulder the responsibility for the success of wedding events. It means that for a wedding event to succeed and the event planner to realize return on investment, there is need to reflect these risk factors into the wedding budget, which may escalate the total cost to the wedding couple and make the event company less competitive. For this reason, a careful balancing between risk and rewards is necessary to cushion the event management firm from adverse outcomes without losing the client to competitors.

Event operation followed as the second EMBOK domain that potentially influenced performance of wedding event management service providers. A number of event operation factors were especially salient. Among them, the experience of the staff team took the lead as the most essential determinant of event management success. Time management was also a critical success factor in tow, as was budgetary issues, whereby difficulty in accurately estimating the budget due to price fluctuations was a key challenge confronting player in the wedding industry.

Event operation factors also did potentially influence performance of wedding event management companies although not as much as event risk or administration domains. On this respect, attention was paid to guest experience, 
understandably because they are potential source of business. Related to this was alertness to signs of communication breakdown. The implication of this is that impression management is required and this calls for a knack for communication vigilance and good interpersonal relations and public relations, both of which touches on the competence of the human resource team. This is supported by past studies of the determinants of event management success such as the study by Shi (2020) which underscored the importance of cultivating a demeanor that that facilitate customers' positive energy and enthusiasm. Further, performance was significantly influenced by the choice of wedding site, which had direct implications on the wedding budget and indirectly, through its impact of other cost factors.

\section{Conclusion}

From a theoretical stance, the EMBOK framework first pioneered by O'Toole (1999) and advanced by Silvers (2007) is validated by this research as a viable framework for theorizing the factors influencing event management success in Kenya's wedding sub-sector. As has been demonstrated in this study, all the three domains studied are crucial to event management performance as various dimensions of performance such as customer satisfaction, budget efficiency, time efficiency and profitability were affected. As can be deduced from the findings, the responsibility of bearing wedding event risks, event management companies should develop risk-adjusted budgets that should inform quotation decisions. Such budgets should provide for security, health and safety contingency plans which should be discussed and negotiated with the client beforehand. An observation of this study is that event management companies may need to refocus their attention to financial performance since they are already doing well in non-financial aspects of performance such as customer satisfaction and time efficiency. Similarly wedding budgets need to be informed by a thorough research and forecasting of future prices and changes that may take place on the event date.

\section{Acknowledgements}

The authors are very grateful to our respondents who took their time to provide adequate information for this study. Without your input, coming up with this article would not have been possible. We truly appreciate you.

\section{References}

i. Abbot, L. J. \& Geddie, M. W. (2001). Event and venue management: Minimizing liability through effective crowd management techniques. Event Management, 6(1), 259-270.

ii. Abson, E. (2017). How event managers lead: Applying competency school theory to event management. Event Management, 21(1), 403-419.

iii. Ahmad, N. L., Yusuf, A. N. M., Shobri, N. D. M., \& Wahab, S. (2012). The relationship between time management and job performance in event management. Procedia-Social and Behaviorial Sciences, 65(2012), 937-941.

iv. Creswell, J. W. (2014). Research design: Qualitative, quantitative, and mixed methods approaches. London, UK: Sage.

v. Denscombe, M. (2014). The good research guide: For small-scale social research projects. New York, NY: McGraw Hill Education.

vi. Fincham, J. E. (2008). Response Rates and Responsiveness for Surveys, Standards, and the Journal. American Journal of Pharmaceutical Education, 72(2), 1-3.

vii. Goldsmith, P. (2018). Big fat African weddings: Commercialization of traditional culture, and its consequences. Retrieved on $9^{\text {th }}$ October 2020 from https://pdfs.semanticscholar.org/c626/9d86f79381f398ea62414df0b19aaa7724c9.pdf

viii. Groves, R. M., Fowler, F. J., Couper, M. P., Lepkowski, J. M., Singer, E., \& Tourangeau, R. (2009). Survey methodology. New York, NY: John Wiley \& Sons.

ix. Kashef, T. E. (2015). What is the value of event management education? The views of six industry practitioners. Event Management, 19(1), 1-13.

x. Kimani, J. N. (2014). Factors influencing performance of events management firms in Nairobi, Kenya. (Unpublished Thesis, University of Nairobi, Kenya).

xi. Kokolakis, S. (2018). Critical success factors and their implementation in sports events organization and management. (Unpublished Doctoral Thesis, University of Stirling Scotland, United Kingdom).

xii. Korir, J. C. (2018). Networking dimensions and performance of event management ventures in Kenya. Research in Hospitality Management, 8(1), 47-54.

xiii. Kruger, E. A. (2011). A stakeholder perspective on mega-event as an element of tourism destination competitiveness. (Unpublished Master's Thesis, University of Pretoria, South Africa).

xiv. Kukushkina, V. (2016). Innovations in hospitality sector innovations in management. (Institute of Hospitality Management in Prague, Czech Republic).

xv. Locacinska, A. (2013). An analysis of audience experiences during a range of planned events in Ireland and how these can be influenced by event design. (Unpublished Master's Thesis, Liverpool John Moores University, Liverpool).

xvi. Makda, T., Bayat, M. S., \& Ukpere, W. I. (2012). Risk management within the events industry in Cape Town, South Africa. African Journal of Business Management, 6(20), 6243-6253.

xvii. Mugenda, A.G., \& Mugenda, O.M. (2003). Research Methods: Quantitative \& qualitative approaches. Nairobi: Acts Press.

xviii. Mwanza, E. (2019). Kenyans spent Ksh. 15 billion on weddings in 2018 - report. Retrieved on $10^{\text {th }}$ October 2020 from https://www.kenyans.co.ke/news/38831-kenyans-spent-ksh15-billion-weddings-2018-report 
xix. Njoroge, E. (2018). Effects of strategic planning on organizational performance: A case of event planning firms in Nairobi CBD. (Unpublished Master's Thesis, United States International University - Africa, Kenya).

xx. Owusu-Mintah, S. O. \& Dacosta, F. D. (2017). A study of events organized by hospitality industries in Accra, Ghana. African Journal of Hospitality, Tourism and Leisure, Volume 6(4), 1-12.

xxi. Reid, S. \& Ritchie, B. (2011). Risk management: event managers' attitudes, beliefs, and perceived constraints. Event Management, 15(1), 329-341.

xxii. Rofna, A. (2009). Critical success factors of international sport events from the perspective of project management. (Unpublished Master's Thesis, Umea University School of Business, Sweden).

xxiii. Shi, J. (2020). Factors influencing customer satisfaction in event planning industry. (Unpublished Masters' Thesis, California State Polytechnic University, Pomona).

xxiv. Silvers, J. R. (2007). Introduction to EMBOK: The event management body of knowledge. Retrieved on $10^{\text {th }}$ October 2020 from http://www.ulviyaman.com/data/TheEventManagementBodyOfKnowledge.pdf

xxv. Sonder, M. (2005). Event Entertainment and Production. Hoboken, NJ: John Wiley\& Sons, Inc.

xxvi. Srivastava, N. \& Maitra, R. (2016). Key performance indicators (KPI) in hospitality industry: An emphasis on accommodation business of 5-star hotels of National Capital Region. International Journal of Research in Tourism and Hospitality, 2(1), 34-40.

xxvii. Terzi, M. C., Sakas, D. P., \& Seimenis, I. (2013). Procedia-Social and Behavioral Sciences, 73(2013), 363-372.

xxviii. Wabuyele, C. K. (2017). Development process for exclusive events start-up business. (Unpublished Thesis, Laurea University of Applied Sciences, Finland).

xxix. Wanjiru, C. (2012). The competitive strategies adopted by events management companies in Nairobi, Kenya. (Unpublished Master's Thesis, University of Nairobi, Kenya). 